\title{
Original Article \\ Bone marrow morphological changes in patients of chronic myeloid leukemia treated with imatinib mesylate
}

\author{
Joshi S, Sunita P, Deshmukh C, Gujral S, Amre P, Nair CN \\ Department of Pathology, Hemato-Oncology Laboratory and Cytogenetics Division, Tata Memorial \\ Hospital, Mumbai, India.
}

Correspondence to: Dr. Sumeet Gujral, E-mail: s_gujral@hotmail.com

\begin{abstract}
BACKGROUND: Imatinib mesylate has shown promising results in chronic myeloid leukemia $(\mathrm{CML})$ in all phases. This drug is an effective treatment for patients with $\mathrm{CML}$ in chronic phase as it induces hematological remission in nearly all patients and cytogenetic responses in many. The bone marrow changes produced by this drug are different from the treatment modalities used earlier in CML. MATERIALS \& METHODS: We studied 80 patients of CML on treatment with Imatinib at doses of 400-800 mg per day. Morphological and cytogenetic evaluation (Ph analysis) of bone marrow aspirates was done at six months of treatment. RESULT: In our study, 95\% (76 out of 80 ) patients showed complete hematological response and $63.3 \%$ showed major cytogenetic response at the end of six months of treatment. The most commonly observed changes in the bone marrow aspirates at the end of six months of therapy were in the form of reduction in the cellularity, reduction in the $M$ : E ratio to a mean of 2:1, presence of relative erythroid hyperplasia, normalization of megakaryocytic morphology and variable increase in the bone marrow lymphocytes. None of these changes had significant correlation with the patient's Ph status. CONCLUSION: We advise study of trephine biopsies to overcome the often-faced problem of hemodiluted aspirates in these cases and evaluation of sequential bone marrows to check the durability of these morphological changes and their correlation with the cytogenetic response with emphasis on cytogenetic changes other than Ph positivity.
\end{abstract}

Key words: Bone marrow, chronic myeloid leukemia, imatinib mesylate, morphology.

\section{Introduction}

Chronic myeloid leukemia (CML) is a clonal stem cell disorder associated with the reciprocal translocation between chromosomes 9 and 22 resulting in formation of the bcr-abl chimeric protein with tyrosine (abl) kinase activity. ${ }^{[1]}$ The enhanced tyrosine kinase activity has been associated with expansion of the pluripotent stem cells, defective adhesion and decreased apoptosis of the hematopoietic cells. ${ }^{[1]}$

The effects of abl kinase activity have been found to be successfully reversed by a novel molecule STI571 or I matinib Mesylate which specifically binds to the ATP binding site of the bcr-abl kinases and inhibits them. ${ }^{[2]}$ I matinib mesylate has shown promising results in chronic myeloid leukemia in all phases. This drug is an effective treatment for patients with $\mathrm{CML}$ in chronic phase as it induces hematological remission in nearly all patients and cytogenetic responses in many. ${ }^{[1]}$ Its efficacy, specificity and the safety profile makes it a strong contender for the first line therapy in $\mathrm{CML}$.

Bone marrow aspirates in a case of $\mathrm{CML}$ at diagnosis typically show hypercellular marrow with marked myeloid hyperplasia and $\mathrm{M}$ : $\mathrm{E}$ ratio usually more than 10:1.The maturation arrest in the myeloid series is variable with presence of a myelocyte peak and blast percentage varies with the phase of the disease. M egakaryocytes are increased with clustering and presence of dyspoietic changes in the form of nuclear hypolobations and micromegakaryocytes [Figure 1]. Basophils are often increased. Eosinophilia and presence of sea blue histiocytes are usual findings. Trephine

The manuscript was presented at the Annual conference of Indian Society of Hematology and Transfusion Medicine, CMC, Vellore, on $19^{\text {th }}$ November 2004 


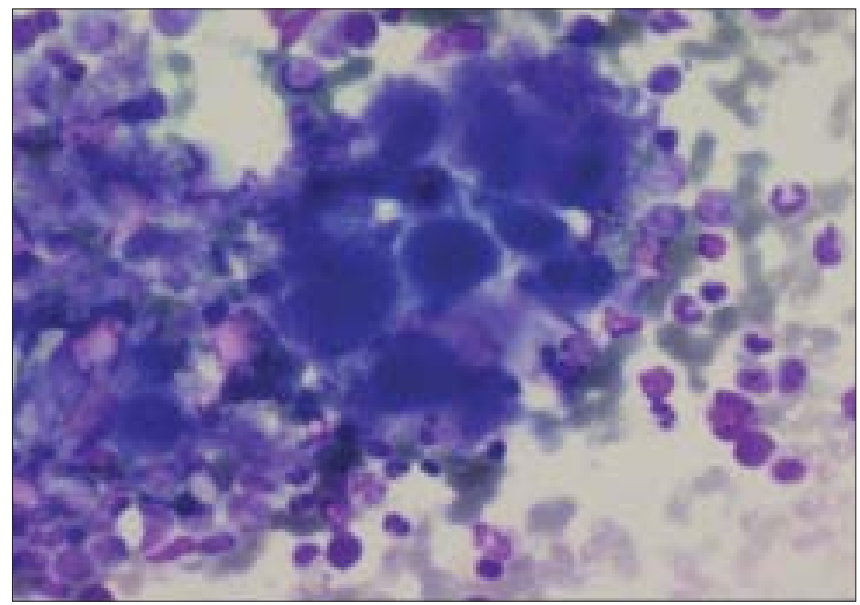

Figure 1: Clustering of dyspoietic megakaryocytes in a new case of CML

biopsy may show variable reticulin fibrosis. These features are due in part to the abnormal hematopoietic differentiation mediated by bcr-abl kinase activity as well as production of PDGF by the CML cells. ${ }^{[1]}$

We examined the morphological features of bone marrow aspirate samples of patients with $C M L$ who received I matinib in order to assess the effects of bcr-abl kinase inhibition produced by this drug. We also correlated these effects with the persistence of the abnormal $\mathrm{Ph}$ positive clone as assessed by the conventional cytogenetic studies.

\section{Aims and Objectives}

1. To evaluate the morphological changes in the peripheral blood and bone marrow of patients of CML treated with I matinib M esylate.

2. To correlate these changes with the cytogenetic response.

\section{Materials and Methods}

A total of 80 either pre treated (with hydroxyurea or interferon) or chemo naive patients of $\mathrm{Ph}$ positive $C M L$ receiving Imatinib were studied retrospectively. A complete clinical data was recorded [Table 1].

The criteria for the diagnosis of CML were:

1. Peripheral blood: Leucocytosis with a variable shift to left in the myeloid cells with presence of a myelocyte peak, absolute basophilia and a low leucocyte alkaline phosphatase score (less than 30 )

2. Bone marrow examination: Increased marrow cellularity with myeloid hyperplasia associated with variable increase in the blasts, basophilia, eosinophilia and megakaryocytic hyperplasia with dyspoietic features.

3. Cytogenetics: Conventional cytogenetics showing presence of $t \quad(9 ; 22)$ translocation i.e. Ph chromosome.

Standard criteria were followed to determine the phase of the disease.

\section{Dosage schedule}

Patients received I matinib mesylate as a single dose (300 to $800 \mathrm{mg}$ per day) after the largest meal of the day. Complete blood counts were monitored weekly for the first month, fortnightly thereafter till patient achieved complete hematological remission and then monthly. Bone marrow aspiration was done at the end of six months of therapy for morphological as well as cytogenetic evaluation.

\section{Criteria to assess response to therapy}

1. Complete hematological response: $\mathrm{N}$ ormalization of the peripheral blood counts and absence of splenomegaly.

2. Partial hematological response: Presence of abnormal counts or splenomegaly.

3. Complete cytogenetic response: Total absence of Philadelphia chromosome.

4. Major cytogenetic response: Ph positivity in less than $35 \%$ of the metaphases studied.

5. $\mathrm{M}$ inor cytogenetic response: $\mathrm{Ph}$ positivity in $35-95 \%$ of metaphases.

6. Poor response: $\mathrm{No}$ reduction in the percentage of $\mathrm{Ph}$ positive chromosomes.

Progressive disease was defined by the increase in the blast percentage and abnormal counts. ${ }^{[1]}$

\section{C riteria for the morphological examination of the} bone marrow were: All the aspiration smears were stained by Wright's stain and independently reviewed (including 500 cell differential count) by the two pathologists. The morphological changes were noted and then correlated with the cytogenetic response. $\mathrm{H}$ emodiluted smears were not considered for assessment of marrow cellularity, $\mathrm{M}$ : $\mathrm{E}$ ratio and adequacy of megakaryocytes.

Adequacy of the aspirate: Presence of at least one marrow particle per smear.

C ellularity: Assessed based on the patient's age and comparison with the pretreatment marrow.

M egakaryocyte number: $O$ ne to three cells per low power field $(10 \mathrm{x})$ were considered adequate. ${ }^{[3]}$ 


\section{Results}

76 out of 80 patients (i.e. 95\%) showed normalization of counts with disappearance of blasts from peripheral circulation at the end of six months of therapy thus indicating complete hematological remission ( $\mathrm{CH}$ R). The manual differential count in these cases showed normalization with variable increase in the lymphocytes. The remaining four patients showed progressive disease in the form of persistently high counts with variable percentage of blasts in the blood.

The most commonly observed changes in the bone marrow aspirates at the end of six months of therapy were in the form of reduction in the cellularity i.e. Normocellular [Figure 2] or hypocellular [Figure $3]$, reduction in the $M: E$ ratio to a mean of $2: 1$, presence of relative erythroid hyperplasia, normalization of megakaryocytic morphology [Tables 2 and 3] and variable increase in the bone marrow lymphocytes. Apart from these findings all the aspirates showed large

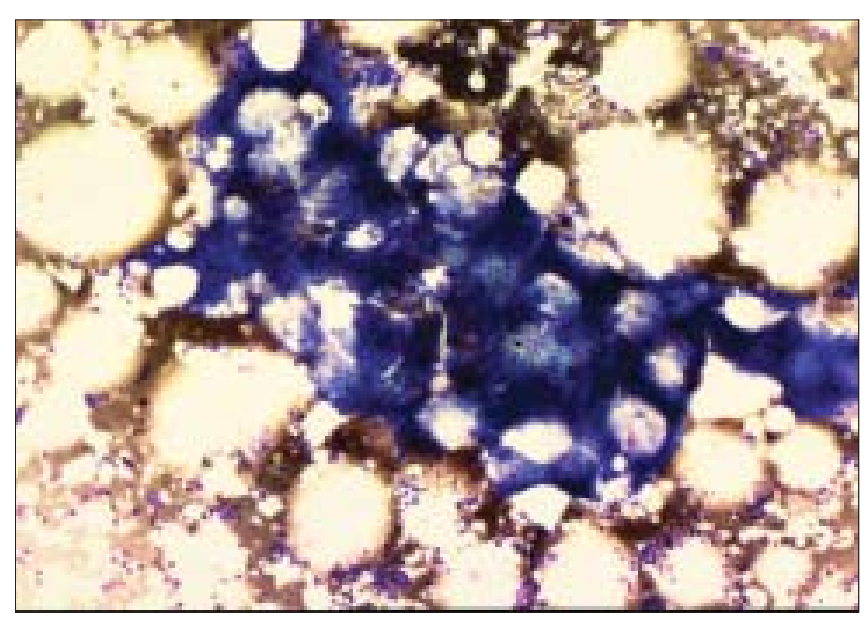

Figure 2: Normocellular marrow particle in a case of CML treated with Imatinib

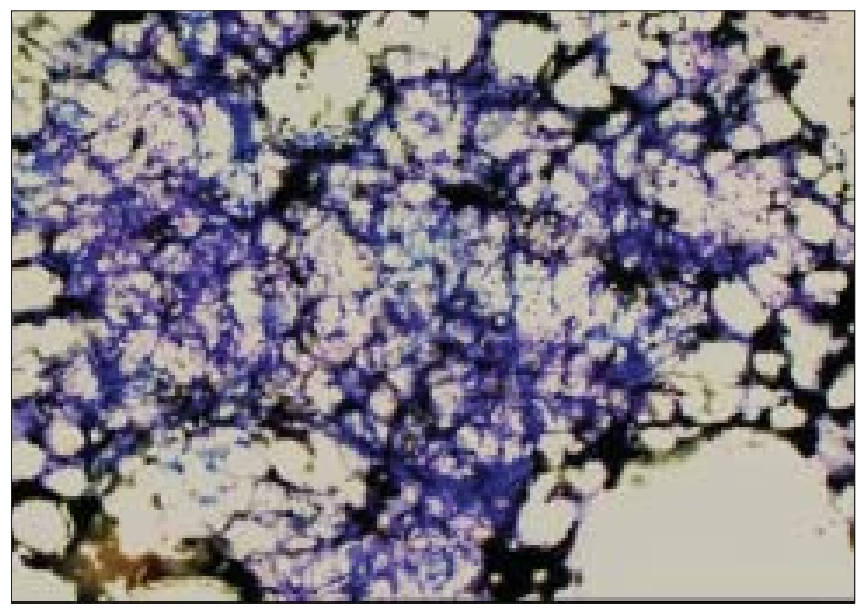

Figure 3: Markedly hypocellular marrow on treatment with Imatinib a number of degenerated cells, presence of sea blue histiocytes and large granular lymphocytes.

12 out of 80 aspirates (15\%) were hemodiluted and hence unsuitable for assessment of marrow cellularity, $\mathrm{M}$ : E ratio and megakaryocyte adequacy.

Although complete hematological response was associated with major cytogenetic response ( $\mathrm{Ph}$ positivity in less than $35 \%$ of the metaphases studied) in $66 \%$ cases, no significant correlation was found between various bone marrow morphological changes and the $\mathrm{Ph}$ status in all the cases studied. So, morphological changes in the bone marrow aspirates of I matinib treated patients of $\mathrm{CML}$ are not predictors of the cytogenetic response.

\begin{tabular}{|c|c|}
\hline \multicolumn{2}{|c|}{ 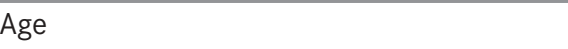 } \\
\hline Median & : 35 years \\
\hline Range & : 5 to 63 years \\
\hline \multicolumn{2}{|l|}{ Sex } \\
\hline Males & $: 56$ \\
\hline Females & : 24 \\
\hline Male: Female ratio & $: \quad 2.3: 1$ \\
\hline \multicolumn{2}{|c|}{ CML status prior to receiving Imatinib } \\
\hline Chronic phase & : 72 \\
\hline Accelerated phase & $: 08$ \\
\hline Blast crisis & : Nil \\
\hline \multicolumn{2}{|l|}{ Hematological response } \\
\hline Complete & : $76(95 \%)$ \\
\hline Progressive disease & : $\quad 04(05 \%)$ \\
\hline \multicolumn{2}{|l|}{ Cytogenetic response } \\
\hline Complete & : $19(25.0 \%)$ \\
\hline Major & $: \quad 31(41.0 \%)$ \\
\hline Minor & : $10(13.0 \%)$ \\
\hline Poor response & $: \quad 16(21.0 \%)$ \\
\hline
\end{tabular}

*Cytogenetic response was not classified into any of these categories in 04 patients with hematological progression of the disease.

Table 2: Peripheral blood changes at 6 months of therapy $(n=80)$

\begin{tabular}{|c|c|c|c|c|}
\hline \multirow{2}{*}{ Parameter } & \multicolumn{2}{|c|}{ Pre-treatment } & \multicolumn{2}{|c|}{ At 6 months } \\
\hline & Range & Mean & Range & Mean \\
\hline $\mathrm{Hb}$ (gm \%) & $6.6-15.9$ & 11.3 & 8.5-15.4 & 12.0 \\
\hline $\operatorname{TLC}\left(X \quad 10^{9} /\right.$ lit. $)$ & $5.4-402.0$ & 77.23 & $1.5-21.4$ & 5.78 \\
\hline $\begin{array}{l}\text { Platelet count } \\
\text { (X } 10^{9} / \text { lit.) }\end{array}$ & $50-1414.0$ & 393.4 & $19-271.0$ & 228.0 \\
\hline
\end{tabular}


Table 3: Morphological changes in the bone marrow

\begin{tabular}{lccc}
\hline Morphological features & No. of cases assessed & No. of cases with the change & Percentage \\
\hline Normalization of cellularity & 68 & 30 & 44.1 \\
\hline Marrow hypoplasia & 68 & 37 & 54.4 \\
\hline Erythroid hyperplasia & 68 & 25 & 36.7 \\
\hline Reduction in megakaryocyte number & 64 & 35 & 54.6 \\
\hline Normalization of megakaryocyte morphology & 64 & 56 & 87.5 \\
\hline Absence of basophils in the marrow & 80 & 63 & 79.0 \\
\hline Increase in marrow lymphocytes & 80 & 80 & 100.0 \\
\hline
\end{tabular}

\begin{tabular}{lccc}
\hline Table 4: Correlation of morphological changes with cytogenetic response & \\
\hline Morphological features & $\begin{array}{c}\text { Patients with } \\
\text { observed } \\
\text { change (\%) }\end{array}$ & $\begin{array}{c}\text { Patients with } \\
\text { major cytogenetic } \\
\text { response (\%) }\end{array}$ & $\begin{array}{c}\text { Correlation with } \\
\text { cytogenetic response } \\
\text { ('P' value) }\end{array}$ \\
\hline Normalization of cellularity & $30 / 68(44.11)$ & $18 / 30(60.0)$ & 0.632 \\
\hline Marrow hypoplasia & $37 / 68(54.4)$ & $18 / 37(48.6)$ & 0.594 \\
\hline Erythroid hyperplasia & $25 / 68(36.7)$ & $13 / 25(52.0)$ & 0.589 \\
\hline Reduction in megakaryocyte number & $35 / 64(54.6)$ & $23 / 35(65.0)$ & 0.644 \\
\hline Normalization of megakaryocyte morphology & $56 / 64(87.5)$ & $35 / 56(62.5)$ & 0.481 \\
\hline Absence of basophils in the marrow & $63 / 80(79.0)$ & $38 / 63(60.3)$ & 0.393 \\
\hline Increase in marrow lymphocytes & $80 / 80(100)$ & $50 / 76(65.7)$ & 0.543 \\
\hline
\end{tabular}

\section{Discussion}

Imatinib mesylate is a novel therapy which has been designed specifically against a selective target (bcr-abl tyrosine kinase). It also inhibits additional tyrosine kinases namely platelet derived growth factor (PDGF) and stem cell factor (c-kit) which might reflect the effects of this drug on non neoplastic marrow elements ${ }^{[4]}$ and hence, the morphological changes which are different from those produced by therapeutic modalities used earlier like $\mathrm{H}$ ydroxyurea and interferon alpha which result in the normalization of peripheral counts but the marrow abnormalities persist. ${ }^{[2]}$

There are very few reports in the literature describing the bone marrow morphological changes in patients of CML treated with Imatinib and their correlation with the cytogenetic response. $\mathrm{H}$ asserjihan et al, have described bone marrow changes in 53 patients on Imatinib in the form of reduction in the overall marrow cellularity, $\mathrm{M}$ : E ratio, marrow fibrosis and megakaryocyte number and clustering. Patients in their study whose marrow showed a decrease in marrow cellularity to $50 \%$ or less were found more likely to experience a cytogenetic response $(p=0.04)$. H owever, none of the other changes showed such correlation. ${ }^{[1]}$
$\mathrm{N}$ one of the morphological changes described in our study had significant correlation with the cytogenetic response [Table 4] which implies that I matinib affects the differentiation pattern of precursor cells expressing the bcr-abl fusion gene but may not kill the malignant clone always. This also explains the oft-seen discordance between complete hematological response and complete/ major cytogenetic response and hence, raises the possibility of achieving a better synergistic effect with combination therapy.

All eight patients in the accelerated phase of CM L showed complete hematological remission at six months of therapy. Bone marrow changes in these patients were also similar to those observed in the patients in chronic phase before starting the therapy.

Braziel et al, McN amara et al and Frater et al, have also reported that the bone marrow of I matinib treated patients shows little or no morphologic evidence of $C M L$ beyond the first five months of therapy. ${ }^{[2,5,6]}$

In our study, $95 \%$ (76 out of 80 ) of the patients were in complete hematological remission and $63.3 \%$ (50 out of 76) showed major cytogenetic response at the end of six months of treatment. The incidence of 
erythroid hyperplasia (25 out of 68 i.e. $36.7 \%$ ) was lower in our study and this change as an indicator of myelosuppression was not found to have any adverse effect on the cytogenetic response. Sneed et al, have described it as an independent poor prognostic factor for achieving the cytogenetic response. ${ }^{[7]}$ Increase in the lymphocytes in the peripheral blood as well as bone marrow of the patients of CML treated with I matinib has not been reported in any of the studies mentioned above.

All the 80 patients in our study showed increase in marrow lymphocytes in the range of 12 to $75 \%$ with a median of $30 \%$. We also noted that this increase in the lymphocytes was absolute, definitely related to the therapy and did not correlate with the Ph status. The exact mechanism for this increase in the lymphocytes is not known. However, since this is a consistent finding, detailed immunological studies are needed to study their role in the tumor immunity.

Various bone marrow changes described in our study can be related to the action of Imatinib on the Ph positive as well as $\mathrm{Ph}$ negative marrow elements irrespective of the cytogenetic response in these patients. In addition, longterm action of this drug on the bone marrow stem cells may give rise to additional chromosomal alterations as observed with other chemotherapeutic agents need to be studied every time along with the Ph status evaluation. ${ }^{[8,9]}$

Study of trephine biopsies is essential in all the cases to overcome the often faced problem of hemodiluted aspirates and is also needed for better assessment of marrow cellularity, M: E ratio and megakaryocyte adequacy and morphology. We also emphasize a need for study of sequential marrows to check the durability of the morphological changes and their correlation with drug resistance, disease relapse and clonal evolution. As Imatinib Mesylate is a commonly used drug in all phases of $C M L$, it is essential for all the hematologists to be aware of the morphological changes produced by this drug.

\section{References}

1. Hasserjian RP, Boecklin F, Parker S, Chase A, Dhar S, Zaiac M, et al. STI571 reduces bone marrow cellularity and normalizes morphologic features irrespective of cytogenetic response. Am J Clin Pathol 2002; 117:360-7.

2. Braziel RM, Launder TM, Druker BJ, Olson SB, Magenis RE, Mauro $\mathrm{MJ}$, et al. Hematopathologic and cytogenetic findings in Imatinib mesylate treated CML patients: 14 months experience. Blood 2002; 100:435-41.

3. Hutchison RE, Davey FR. Hematopoiesis. In: John B. Henry's Clinical Diagnosis and management by laboratory methods. $19^{\text {th }} \mathrm{ed}$. Philadelphia: 1996. p. 594-616.

4. Druker BJ, Tamura S, Buchdunger E, Ohno S, Segal GM, Fanning S, et al. Effects of a selective inhibitor of the Abl kinase on the growth of bcr-abl positive cells. Nat Med 1996;2:561-6.

5. McNamara C, Grigg A, Szer J, Roberts A, Campbell L, Hoyt R, et al. Morphological effects of Imatinib mesylate (STI571) on the bone marrow and blood of patients with $\mathrm{Ph}$ chromosome positive chronic myeloid leukemia. Clin Lab Hematol 2003;25:119-25.

6. Frater JL, Tallman MS, Variakojis D, Druker BJ, Resta D, Riley MB, et al. Chronic myeloid leukemia following therapy with Imatinib Mesylate. Am J Clin Pathol 2003;119:833-41.

7. Sneed TB, Kantarjian HM, Talpaz M, O'Brien S, Rios MB, Bekele BN, et al. The significance of myelosuppression during therapy with Imatinib mesylate in patients with CML in chronic phase. Cancer 2004; 100:116-21.

8. Patil SR, Corder MP, Jochimsen PR, Dick FR. Bone marrow chromosomal abnormalities in human cancer patients following adjuant chemotherapy. Cancer Res 1980;40:4076-80.

9. Maloisel F, Uettwiller F, Laplace A, Lioure B, Herbrecht R, Mark $\mathrm{M}$, et al. Emergence of unusual cytogenetic abnormalities under interferon alfa therapy in patients with CML. Cancer Genet Cytogenet 1999;113:172-6.

Source of Support: Nil, Conflict of Interest: None declared. 